\title{
PENERAPAN DAN SOSIALISASI GOOD MANUFACTURING PRACTICES (GMP) DI INDUSTRI RUMAH TANGGA (IRT) TAHU DI KECAMATAN CIPONDOH
}

\section{The Implementation and Socialization of Good Manufacturing Practices in the Household Industry of Tofu in Cipondoh District}

\author{
Mohamad Haifan ${ }^{1)}$ Raskita Saragih ${ }^{2)}$ Asmi Lara Florida ${ }^{3)}$ \\ 1) Program Studi Teknik Mesin Otomotif, Institut Teknologi Indonesia, email: haifanmohamad1963@gmail.com \\ ${ }^{2)}$ Program Studi Teknologi Industri Pertanian, Institut Teknologi Indonesia, email: raskitasaragih@yahoo.com \\ ${ }^{3)}$ Program Studi Teknologi Industri Pertanian, email: asmilaraflorida@gmail.com
}

\begin{abstract}
ABSTRAK
Pangan yang aman, bermutu dan bergizi memiliki peran penting pada peningkatan derajat kesehatan dan kecerdasan masyarakat. Untuk menghasilkan pangan yang aman dan bermutu baik bagi kesehatan, industri perlu menerapkan Good Manufacturing Practices (GMP) dalam proses produksinya. Kegiatan pengabdian masyarakat ini bertujuan: 1) untuk mengkaji sejauh mana penerapan GMP di industri rumah tangga (IRT) yang memproduksi tahu di Kecamatan Cipondoh, Kota Tangerang, 2) sosialisasi hasil kajian GMP kepada pemilik dan pekerjai guna meningkatkan kesadaran untuk memperbaiki sarana dan proses produksinya. Metode yang dilakukan melalui pendekatan diskriptif dan partisipatif, sedangkan penentuan lokasi kegiatan dilakukan secara purposive. Pengumpulan data dilakukan dengan pengamatan langsung dan wawancara mendalam kepada pemilik/ pengelola IRT tersebut. Selanjutnya hasil pengamatan di lokasi dibandingkan dengan form Pedoman CPPB-IRT (HK. 00.05.5.1639). Sosialisasi penerapan dan penilaian GMP kepada kepada pemilik/ pengelola dan pekerja IRT dilakukan dengan ceramah dan diskusi/ tanya jawab. Hasil penilaian IRT tahu menunjukkan total 10 penyimpangan minor, 6 penyimpangan mayor, 7 penyimpangan serius, dan 12 penyimpangan kritis. Mengacu pada formulir pemeriksaan CPMB (BPOM, 2012) dikategorikan dalam rating IV, dengan hasil penilaian D (kurang). Sosialisasi penerapan dan penilaian GMP kepada pemilik/pengelola dan pekerja meningkatkan pemahaman dan kesadaran untuk perbaikan sarana dan prasarana serta proses produksinya secara bertahap.
\end{abstract}

Kata Kunci : Keamanan Pangan, Industri Rumah Tangga, Tahu, Good Manufacturing Practices (GMP), Sosialisasi Hasil Penilaian.

\section{ABSTRACT}

Food that is safe, quality and nutritious has an important role in increasing the health and intelligence of the people. To produce safe and good quality food for health, the industry needs to implement Good Manufacturing Practices (GMP) in the production process. This community service activity aims: 1) to assess the extent of the application of GMP in the home industry (IRT) that produces tofu in Cipondoh District, Tangerang City, 2) dissemination of GMP study results to owners and workers in order to increase awareness to improve facilities and production processes. The method is done through a descriptive and participatory approach, while determining the location of activities is done purposively. Data collection is done by direct observation and in-depth interviews with the owner / manager of the IRT. Furthermore the results of observations at the site are compared with the CPPBIRT Guideline form (HK. 00.05.5.1639). The dissemination of GMP implementation and assessment to IRT owners / managers and workers is carried out with lectures and discussions / questions and answers. The results of the IRT tofu assessment showed a total of 10 minor deviations, 6 major deviations, 7 serious deviations, and 12 critical deviations. Referring to the CPMB examination form (BPOM, 2012), it is categorized in rating IV, with an assessment result $D$ (less). The dissemination of GMP implementation and assessment to owners / managers and workers increases understanding and awareness for the gradual improvement of facilities and infrastructure and the production process.

Key words: Food Safety, Home Industry, Tofu, Good Manufacturing Practices (GMP), Socialization of Assessment Results. 


\section{PENDAHULUAN}

Pangan yang aman, bermutu dan bergizi merupakan faktor penting untuk meningkatkan derajat kesehatan dan kecerdasan masyarakat. Oleh karena itu, keamanan dan kualitas pangan harus selalu diupayakan agar masyarakat sebagai pengguna produk pangan tersebut dapat terhindar dari penyakit dan/ atau keracunan pangan [1]. Faktor keamanan pangan berkaitan dengan tercemarnya pangan oleh cemaran mikrobiologis, logam berat, dan bahan kimia yang membahayakan kesehatan [2]. Berkaitan dengan aspek keamanan pangan, masalah keracunan pangan masih menjadi isu penting yang perlu mendapatkan perhatian serius berbagai pihak, yaitu pemerintah, industri dan masyarakat.

Kasus keracunan pangan secara nasional masih sekitar 20 juta kasus per tahunnya [3]. Dari beberapa kasus keracunan tersebut, mengindikasikan bahwa masalah mutu dan keamanan pangan menjadi semakin penting dan perlu pengawasan dan pengendalian secara khusus. Di sisi lain, tuntutan jaminan mutu dan keamanan pangan terus meningkat sejalan dengan kesadaran masyarakat terhadap mutu dan keamanan pangan yang dikonsumsi. Untuk itu, pengawasan dan pengendalian terhadap mutu dan keamanan pangan harus mampu mengimbangi perkembangan dan kemajuan di bidang industri pangan saat ini.

Good Manufacturing Practices (GMP) atau Cara Produksi Pangan yang Baik (CPPB) adalah suatu pedoman cara berproduksi makanan yang bertujuan agar produsen memenuhi persyaratan-persyaratan yang telah ditentukan. Dengan menerapkan CPPB diharapkan produsen pangan dapat menghasilkan produk makanan yang bermutu, aman dikonsumsi dan bergizi sesuai dengan tuntutan konsumen, bukan hanya konsumen lokal tetapi juga konsumen global. Dengan berkembangnya industri pangan yang menghasilkan pangan yang bermutu dan aman untuk dkonsumsi, sehingga masyarakat secara umum akan terlindung dari penyimpangan mutu pangan dan bahaya yang mengancam kesehatan. Penerapan CPPB untuk industri rumah tangga (IRT) memiliki tujuan, yaitu tujuan umum adalah menghasilkan pangan yang bermutu, aman dikonsumsi dan sesuai dengan tuntutan konsumen baik konsumen domestik maupun internasional, sedangkan tujuan khusus adalah : (a) memberikan prinsip-prinsip dasar dalam memproduksi pangan yang baik, (b) mengarahkan IRT agar dapat memenuhi berbagai persyaratan produksi yang baik seperti persyaratan lokasi, bangunan dan fasilitas, peralatan produksi, pengendalian hama, higiene karyawan, pengendalian proses dan pengawasan [4].
Permasalahan mutu dan keamanan pangan pada produk pengolahan pangan sering terjadi pada produk yang diproduksi pada industri kecil atau industri rumah tangga (IRT). Hal ini dikarenakan tingkat pengetahuan dan kesadaran pengelola/ pemilik IRT terhadap mutu dan keamanan pangan masih rendah [5].

Tahu merupakan salah satu makanan yang cukup populer di Indonesia. Tahu banyak dikonsumsi hampir dari seluruh kalangan, mulai dari kalangan bawah hingga kalangan atas. Permintaaan tahu yang cukup tinggi mendorong pertumbuhan industri pembuatan tahu pada industri skala rumah tangga. Kawasan IRT tahu di Kecamatan Cipondoh merupakan sentra industri kecil/ IRT di wilayah Kota Tangerang. Dari hasil kunjungan/ observasi di lokasi, beberapa pemilik/pengelola IRT masih belum memahami GMP/ CPPB pada aktivitas industrinya. Untuk itu kegiatan pengabdian kepada masyarakat ini dilakukan bertujuan untuk melakukan penilaian sejauhmana IRT tahu telah menerapkan GMP/CPPB. Hasil penilaian selanjutnya disosialisasikan kepada pengelola/ pemilik untuk perbaikan kondisi sarana dan prasaran serta proses produksinya untuk meningkatkan kualitas dan keamanan produk yang dihasilkan.

\section{METODE}

Kegiatan pengabdian kepada masyarakat dilaksanakan di sentra IRT tahu di wilayah Kecamatan Cipondoh, Kota Tangerang. Pemilihan lokasi IRT dilakukan secara purposive dengan kriteria kapasitas produksinya cukup besar dan tenaga kerjanya cukup banyak dibanding IRT lain yang terdapat di wilayah tersebut.

Penilaian kondisi sarana dan prasarana serta proses produksi dilakukan dengan cara observasi langsung dan wawancara mendalam dengan pemilik/ pengelola IRT tersebut. Selanjutnya hasil observasi/ pengamatan dibandingkan dengan form Pedoman CPPB-IRT (HK. 00.05.5.1639). Hasil penyimpangan minor, mayor, serius dan kritis IRT tahu sebagai acuan dalam perbaikan sarana dan prasarana serta proses produksi.

Kegiatan sosialisasi dilakukan kepada pemilik/ pengelola dan pekerja IRT tahu terhadap tujuan dan makna penting GMP dan hasil penilaian penerapan GMP di IRT tersebut. Target sosialisasi memberikan pengetahuan tentang GMP yang diharapkan dapat membangun kesadaran pemilik/pengelola serta karyawannya untuk meningkatkan sarana dan prasarana serta proses produksinya ke depannya.

\section{HASIL DAN PEMBAHASAN}

Berdasarkan kriteria pemilihan IRT tahu secara purposive dipilih IRT tahu yang memiliki karyawan 
sebanyak 12 orang dengan kapasitas produksi tahu kuning sebanyak 20.000 potong per hari. Produk tahu yang dihasilkan dipasarkan ke wilayah Kota Tangerang dan sekitarnya.

Target penerapan GMP pada industri pangan untuk memperkecil atau menghilangkan sama sekali faktor yang dapat menurunkan mutu produk seperti kontaminasi dan kesalahan berproduksi. GMP yang mengacu pada Pedoman CPPB-IRT (HK.00.05.5.1639) terdiri atas lokasi dan lingkungan produksi, bangunan dan fasilitas IRT, peralatan produksi, suplai air, fasilitas kegiatan higienis dan sanitasi, pengendalian hama, kesehatan dan higienie karyawan, pengendalian proses, label pangan, penyimpanan, penanggung jawab, penarikan produk, pencatatan dan dokumentasi dan pelatihan karyawan.

\section{Lokasi dan Lingkungan Produksi}

Dalam menetapkan lokasi industri seharusnya berada di lokasi yang bersih, bebas dari sampah, bau, asap, kotoran dan debu. Jika lingkungan berpotensi sebagai sumber pencemaran, maka perlu dilakukan tindakan pencegahan untuk melindungi pangan yang diproduksi.

Secara umum lokasi pabrik sudah cukup baik dan memenuhi kriteria, diantaranya berada pada kawasan yang terbebas dari polusi/cemaran dari industri lain, berada jauh dari tempat pembuangan sampah, dan tidak berada di wilayah yang berpotensi banjir. Namun yang menjadi kelemahan, industri berada di area perkampungan padat penduduk yang dikhawatirkan dapat menganggu keberadaan industri tersebut.

\section{Bangunan dan Fasilitas}

Beberapa pertimbangan dalam mendesain bangunan industri pangan terkait dengan sanitasi, diantaranya tata letak, lantai, dinding, langit-langit/ plavon, ventilasi, dan pintu yang kemungkinan akan memunculkan serangga yang dikhawatirkan menimbulkan pencemaran pada produk pangan.

Secara umum, desain dan konstruksi pabrik sudah sesuai dengan kapasitas produksi yang yang dilakukan oleh IRT, kapasitas produksi belum terlalu besar, sehingga masih dapat ditampung pada ruang produksi. Kondisi lantai belum seluruhnya berbahan keramik, kemiringan lantai belum diperhatikan dengan baik, sehingga ditemukan genangan air di ruang produksi yang mengakibatkan licin dan membahayakan pekerja. Selain itu, terdapat saluran limbah di ruang produksi yang tidak tertutup, sehingga dikahwatirkan menimbulkan pencemaran terhadap produk.

\section{Suplai Air}

Industri tahu membutuhkan air untuk melakukan proses sortasi, perendaman, pengupasan kulit, pencucian, penggilingan, perebusan, dan penyaringan. Air baku pada industri pengolahan pangan harus memenuhi kriteria, diantaranya bebas bakteri, bebas senyawa kimia berbahaya, tidak berwarna, tidak berbau, bebas dari gas (hydrogen sulfida serta mineral besi dan mangan) dan tidak keruh. Beberapa jenis bakteri yang terdapat dalam air, antara lain Streptococcus faecalis dan Clostridium perfringens. Bakteri tersebut dapat berasal dari hewan, bahan buangan dan kotoran manusia.

Sumber air yang digunakan dalam proses produksi di IRT tahu bersumber dari PAM, sehingga memenuhi persyaratan produksi tahu. Namun suplai air PAM terkadang tidak stabil, sehingga terkadang IRT memanfaatkan air tanah dengan pengawasan kualitas.

\section{Higienis dan Sanitasi}

Sanitasi yang baik tidak hanya pada kebersihan bahan baku, melainkan juga peralatan, ruang, pekerja, penanganan dan pengolahan limbah juga sangat berpengaruh terhadap produk yang dihasilkan [6]. Kebersihan ruang produksi dapat memberi jaminan terhadap kualitas produk yang dihasilkan. Beberapa hal yang perlu diperhatikan diantaranya kondisi peralatan dan kebersihan pekerja. Peralatan produksi harus sesuai dengan persyaratan, diantaranya tidak mudah berkarat, mudah dibersihkan dan dilengkapi dengan petunjuk penggunaan agar aman saat digunakan.

Dari hasil pengamatan dan wawancara, IRT tahu telah berusaha menjaga kebersihan, namun masih terlihat kondisi langit-langit/plafon dan dinding ruangan yang masih kurang bersih. Peralatan yang dibutuhkan dalam proses produksi telah tersedia, namun tidak dilengkapi dengan panduan petunjuk penggunaan. Pembersihan peralatan dilakukan setelah selesai produksi yang dilakukan oleh pekerja dengan menggunakan sabun detergen dan sedikit campuran klorin.

\section{Kesehatan dan Higienis Pekerja}

Kebersihan dan kesehatan pekerja merupakan aspek penting dalam mendukung produksi yang berakibat langsung terhadap produk yang dihasilkan. Produktifitas karyawan dipengaruhi oleh kondisi lingkungan yang bersih dan sehat. Kenyamanan, kondisi fisik, kebersihan serta kategori pekerjaan dapat mempengaruhi kesehatan pekerja [7].

Berdasarkan pengamatan di lapangan, kesehatan pekerja belum menjadi perhatian serius pemilik/pengelola IRT. Pemeriksanaan kesehatan 
pekerja pada saat masuk kerja belum terlalu diperhatikan, seharusnya pekerja yang kurang sehat tidak boleh masuk kerja karena dapat mengkontaminasi produk. Pemeriksaan berkala (setahun sekali) belum diterapkan kepada pekerja. Selain itu, kebersihan karyawan belum diterapkan dengan ketat, hal ini terlihat pekerja yang tidak memakai baju diperbolehkan memasuki ruang produksi.

\section{Pembuangan Limbah}

Limbah IRT tahu terdiri atas limbah padat dan cair. Air buangan dari proses pengolahan tahu dinamakan limbah cair. Limbah cair industri tahu ini memiliki kandungan senyawa organik yang sangat tinggi. Tanpa proses penanganan yang baik, limbah tahu dapat menyebabkan berbagai dampak negatif seperti polusi air, sumber penyakit, bau tak sedap, meningkatkan pertumbuhan nyamuk, dan menurunkan estetika lingkungan sekitar. Limbah cair yang dibuang ke perairan tanpa pengolahan terlebih dahulu juga dapat mengakibatkan kematian makhluk hidup dalam air termasuk mikroorganisme (jasad renik) yang berperan penting dalam mengatur keseimbangan biologis dalam air.

Di IRT tahu, limbah cair dibuang melalui saluran bak penampung yang terdapat di lingkungan IRT tersebut. Namun masih terlihat limbah cair menggenang di sekitar IRT, sehingga dikhawatirkan mengganggu lingkungan sekitar

\section{Hasil Penilaian GMP}

Secara umum, hasil penilaian GMP IRT tahu menunjukkan total 10 penyimpangan minor, 6 penyimpangan mayor, 7 penyimpangan serius, dan 12 penyimpangan kritis. Dengan demikian, dapat disimpulkan penerapan GMP IRT tahu mengacu pada formulir pemeriksaan CPMB (BPOM, 2012) dikategorikan dalam rating IV, dengan hasil penilaian D (kurang). Nilai kurang (D) artinya terdapat $\geq 4$ penyimpangan kritis, $\geq 21$ penyimpangan serius dan beberapa penyimpangan mayor dan minor.

Penyimpangan pada umumnya terkait dengan konstruksi bangunan, diantaranya (a) dinding tidak dilapisi dengan bahan yang mudah dicuci dan mudah diperbaiki, (b) langit-langit/ plafon tidak dimodifikasi agar mudah dibersihkan dan tahan air, (c) tidak adanya penghilangan sudut pada pertemuan antara dinding dengan lantai, atau antara dinding dan dinding, (d) ruang produksi yang terbuka memungkinkan kontaminasi debu dan serangga dari lingkungan sekitar, (e) tidak adanya fasilitas khusus untuk pencucian tangan sebelum masuk ke ruang produksi dan pengolahan. Rekapitulasi hasil penilaian IRT tahu dapat dilihat pada Tabel 1. Beberapa usulan perbaikan sarana dan prasarana produksi industri/ IRT tahu disajikan pada Tabel 2.

Tabel 1. Hasil rekapitulasi penilaian IRT tahu di wilayah Kecamatan Cipondoh (BPOM, 2012)

\begin{tabular}{|c|l|c|c|c|c|}
\hline \multirow{2}{*}{ No. Aspek Penilaian } & \multicolumn{4}{c|}{ Jumlah Penyimpangan } \\
\cline { 3 - 5 } & & \multicolumn{3}{|c|}{ Industri Tahu } \\
\cline { 4 - 5 } & & $\mathrm{Mi}$ & $\mathrm{Ma}$ & $\mathrm{Sr}$ & $\mathrm{Kr}$ \\
\hline 1 & Lokasi dan Lingkungan Produksi & & 1 & & \\
\hline 2 & Bangunan dan Fasilitas & 2 & & & \\
\hline 3 & Peralatan Produksi & & 1 & 1 & \\
\hline 4 & Suplai Air atau Sarana Penyediaan Air & & 1 & 1 & 2 \\
\hline 5 & Fasilitas dan Kegiatan Higiene dan Sanitasi & 1 & 1 & 2 & 1 \\
\hline 6 & Kesehatan dan Higiene Karyawan & 3 & & & 1 \\
\hline 7 & Pemeliharaan dan Program Higiene dan Sanitasi & 2 & & & \\
\hline 8 & Penyimpanan & 2 & & & 1 \\
\hline 9 & Pengendalian Proses & & & & 2 \\
\hline 10 & Pelabelan Pangan & & & & 2 \\
\hline 11 & Pengawasan oleh Penanggung Jawab Total Penyimpangan & $\mathbf{1 0}$ & $\mathbf{6}$ & $\mathbf{7}$ & $\mathbf{1 2}$ \\
\hline 12 & Penarikan Produk & & 1 & & \\
\hline 13 & Pencatatan dan Dokumentasi & & & 1 & 1 \\
\hline 14 & Pelatihan Karyawan & & & \\
\hline
\end{tabular}

Keterangan : $\mathrm{Mi}=$ Minor, $\mathrm{Ma}=$ Mayor, $\mathrm{Sr}=$ Serius, $\mathrm{Kr}=$ Kritis 
Tabel 2. Usulan perbaikan yang perlu dilakukan pada IRT tahu

\begin{tabular}{|c|c|c|}
\hline No. & Aspek & Perbaikan \\
\hline 1. & Bangunan & $\begin{array}{l}\text { - Good House keeping } \\
\text { - Membangun tempat penyimpanan bahan baku yang terpisah }\end{array}$ \\
\hline 2. & Fasilitas Sanitasi & $\begin{array}{l}\text { - Melakukan pengecekan kualitas air yang digunakan untuk proses } \\
\text { produksi agar memenuhi syarat kualitas air baku } \\
\text { - Memisahkan tempat pembuangan limbah padat dan cair } \\
\text { - Letak toilet berjauhan dengan ruang produksi } \\
\text { - Menyediakan sarana sanitasi khusus untuk karyawan }\end{array}$ \\
\hline 3. & Mesin & $\begin{array}{l}\text { - Melakukan perawatan dan pemeliharaan mesin penggiling kedelai } \\
\text { secara berkala }\end{array}$ \\
\hline 4. & Pengawasan Proses & $\begin{array}{l}\text { - Melakukan pengawasan proses produksi untuk menjamin keamanan } \\
\text { produk tahu }\end{array}$ \\
\hline 5. & Laboratorium & (belum ada) \\
\hline 6. & Karyawan & $\begin{array}{l}\text { - Pekerja harus menggunakan pakaian yang bersih pada saat proses } \\
\text { produksi } \\
\text { - Melakukan pengecekan kesehatan pekerja sebelum melaksanakan } \\
\text { pekerjaan } \\
\text { - Menunjuk salah satu pekerja yang bertugas dan bertanggung jawab } \\
\text { dalam pengawasan proses produksi dan keamanan pangan }\end{array}$ \\
\hline 7. & Pengemas & $\begin{array}{l}\text { - Melakukan perbaikan bahan kemasan agar tahu tidak mudah patah } \\
\text { atau rusak }\end{array}$ \\
\hline 8. & Penyimpanan & $\begin{array}{l}\text { - Mengusahakan ruang penyimpnan kedelai selalu bersih untuk } \\
\text { menghindari hewan perusak } \\
\text { - Melakukan pencatatan terkait informasi bahan baku dan produk }\end{array}$ \\
\hline 9. & $\begin{array}{l}\text { Pemeliharaan dan } \\
\text { Program Sanitasi }\end{array}$ & $\begin{array}{l}\text { - Mesin dan peralatan produksi selalu dibersihkan setelah selesai } \\
\text { produksi } \\
\text { - Ruang produksi, ruang penyimpanan, kantor rutin dibersihkan untuk } \\
\text { menghindari cemaran pada produk } \\
\text { - Pekerja harus sehat dan menggunakan pakaian yang bersih }\end{array}$ \\
\hline 10. & Pengangkutan & $\begin{array}{l}\text { - Pengangkutan produk harus hati-hati untuk menghindari kerusakan } \\
\text { produk }\end{array}$ \\
\hline 11. & $\begin{array}{l}\text { Dokumentasi atau } \\
\text { Pencatatan }\end{array}$ & $\begin{array}{l}\text { - Melakukan pencatatan dan dokumentasi terhadap bahan baku, produk } \\
\text { yang dihasilkan, penyimpanan bahan baku, penggunan energi dan } \\
\text { pemasaran produk }\end{array}$ \\
\hline 12. & Pelatihan & $\begin{array}{l}\text { - Memberikan pelatihan dan arahan kepada pekerja untuk meningkatan } \\
\text { kualitas produk dan produktivitas pekerja }\end{array}$ \\
\hline
\end{tabular}

\section{Sosialisasi Hasil Penilaian GMP}

Sosialisasi adalah proses belajar yang di alami seseorang untuk memperoleh pengetahuan ketrampilan, nilai-nilai dan norma-norma agar ia dapat berpartisipasi sebagai anggota dalam kelompok masyarakatnya [8].

Sosialisasi penerapan dan hasil penilaian GMP perlu dilakukan untuk memberikan pemahaman dan kesadaran untuk melakukan perubahan yang lebih baik. Kegiatan sosialisasi dilakukan kepada pemilik/pengelola dan pekerja IRT tahu dengan cara presentasi dan tanya jawab/diskusi. Dari hasil sosialisasi, pemilik/pengelola dan pekerja mengetahui dan memahami makna dan urgensi penerapan GMP industri tahu yang mempu membangun kesadaran untuk melakukan perbaikan sarana dan prasarana serta proses produksi secara bertahap. Upaya perbaikan ini dilakukan untuk meningkatkan kualitas dan kemanan produk, pada akhirnya akan meningkatkan kepercayaan pelanggan dan omset penjualannya.

\section{OUTCOME}

Kegiatan pengabdian kepada masyarakat penerapan dan sosialisasi GMP di IRT yang memproduksi tahu dimaksudkan untuk memberikan pemahaman mengenai urgensi atau manfaat penerapan cara produksi pangan yang baik, membimbing langsung melakukan penilaian aspekaspek GMP yang mengacu pada Pedoman CPPB-IRT 
(HK. 00.05.5.1639). Aspek penilaian difokuskan pada ketersediaan sarana dan prasarana serta proses produksi, higenis pekerja dan pengelolaan limbah yang akan berpengaruh pada produk tahu yang berkualitas dan aman.

Dampak/outcome dari kegiatan ini mampu meningkatan pemahaman, kesadaran kepada pemilik/pengelola dan pekerja IRT tahu untuk meningkatkan sarana dan prasarana serta proses produksi guna menghasilkan produk tahu yang lebih berkualitas dan aman. Pemilik/pengelola akan melakukan perbaikan sarana dan prasarana secara bertahap. Dengan upaya ini diharapkan akan meningkatkan kepercayaan pelanggan dan meningkatkan pendapatan dari usahanya.

\section{KESIMPULAN}

Hasil penilaian IRT tahu menunjukkan total 10 penyimpangan minor, 6 penyimpangan mayor, 7 penyimpangan serius, dan 12 penyimpangan kritis. Mengacu pada formulir pemeriksaan CPMB (BPOM, 2012) dikategorikan dalam rating IV, dengan hasil penilaian D (kurang). Sosialisasi penerapan dan penilaian GMP kepada pemilik/pengelola dan pekerja meningkatkan pemahaman dan kesadaran untuk perbaikan sarana dan prasarana serta proses produksi tahu secara bertahap.

\section{REFERENSI}

[1] Departemen Kesehatan Republik Indonesia, Jakarta, Bakteri Pencemar Makanan dan Penyakit Bawaan Makanan, 2000.

[2] Aufa Aulia Kanza, Sukma Chaedir Umar, Mutu, Gizi, dan Keamanan Pangan, 2012. https://www.academia.edu/12468426/Buku Mutu-Gizidan-Keamanan-Pangan (diakses pada tanggal 26 Maret 2020).

[3] Badan Pengawasan Obat dan Makanan, 2019, Ada 20 Juta Kasus Keracunan Pangan per Tahun di Indonesia. https://republika.co.id/berita/q0qmtn414/ada20-juta-kasus-keracunan-pangan-per-tahun-diindonesia (diakses pada tanggal 20 April 2020).

[4] Badan Pengawas Obat dan Makanan, Keputusan kepala Badab Pengawas Obat dan Makanan RI Nomor. 00.05.5.1639 tentang pedoman Cara Produksi Pangan yang Baik Untuk Industri Rumah Tangga (CPPB-IRT), 2003.

[5] Ropkins, K and Beck, A. J, Evaluation of worldwide approaches to the use of HACCP to control food safety. Trends in Food Science \& Technology, Vol 11, 2000, pp : 10-21

[6] Pruss, A, Kay, D, Fewtrell, L, and Bartram, J, Estimating the Burden of Disease from Water,
Sanitation, Hygene at a Global Level. Environmental Health Perspectives, 110: 537. 2002.

[7] Fewtrell, L., Kaufmann, R. B., Kay, D, Enanoria, W., Haller, L., and Colford, J. M, Water, sanitation, and hygiene interventions to reduce diarrhoea in less developed countries: a systematic review and meta-analysis. The Lancet Infectious Diseases. 5: 42-52. 2005.

[8] Vander, Zanden J. W. Sociology. New York: John Wiley and Sons. 1989 